\title{
Flow boiling of R245fa in a single circular microchannel
}

\author{
Stefano BORTOLIN, Davide DEL COL ${ }^{*}$, Luisa ROSSETTO \\ * Corresponding author: Tel.: ++39 049 8276891; Fax: ++39 049 8276896; \\ Email: davide.delcol@unipd.it \\ Department of Fisica Tecnica, University of Padova, Italy
}

\begin{abstract}
The present paper describes an experimental setup for the investigation of two-phase heat transfer inside microchannels and reports local heat transfer coefficients measured during flow boiling of HFC-245fa in a $0.96 \mathrm{~mm}$ diameter single circular channel. The test runs have been performed during vaporization at around $1.85 \mathrm{bar}$, corresponding to $31^{\circ} \mathrm{C}$ saturation temperature. As a peculiar characteristic of the present technique, the heat transfer coefficient is not measured by imposing the heat flux; instead, the boiling process is governed by controlling the inlet temperature of the heating secondary fluid. In the data, mass velocity ranges between 200 and $400 \mathrm{~kg} \mathrm{~m}^{-2} \mathrm{~s}^{-1}$, with heat flux ranging between 5 and $85 \mathrm{~kW} \mathrm{~m}^{-2}$ and vapor quality from 0.05 up to 0.8 . Since these data are not measured at uniform heat flux conditions, a proper analysis is performed to enlighten the influence of the different parameters and to compare the present data to those obtained when imposing the heat flux. Besides, test runs have been carried out in a double mode: by increasing the water-to-refrigerant temperature difference and by decreasing it. Finally, the experimental data are compared to models available in the literature for prediction of the heat transfer coefficients inside microchannels.
\end{abstract}

Keywords: Flow boiling, microchannel, R245fa

\section{Introduction}

Recent technical applications in the electronic industry demand high-heat flux dissipation from small areas. Cooling through vaporization of a refrigerant in a minichannel heat sink allows compactness, minimal coolant usage, high heat transfer coefficients and a constant temperature dictated by the coolant's saturation temperature.

For different applications, microchannel flow boiling can also occur when evaporators are used to cool a secondary fluid.

So far there is not any established criterion to properly define the transition between conventional ducts to minichannels and to microchannels. Kew and Cornwell (1997) defined an approximate criterion to draw the line dividing conventional channels and microchannels, which accounts for the characteristic of the fluid, namely surface tension and density. Instead, Kandlikar and Grande (2003) provided a classification which is merely based on the channel diameter. According to them, all the channels with diameter between $0.2 \mathrm{~mm}$ and $3 \mathrm{~mm}$ can be referred to as minichannels. By following this classification, the present test tube should be named minichannel, whereas, according to Kew and Cornwell (1997), a $1 \mathrm{~mm}$ diameter tube working with $\mathrm{R} 245 \mathrm{fa}$ at $30^{\circ} \mathrm{C}$ fits in the microchannel area. Therefore, in the present paper, the words microchannel and minichannel may be used both as a possible denomination.

In two-phase microchannel flow, capillary (surface tension) forces become important, thus impeding stratification of liquid. Bubble flow, elongated (slug) flow, annular flow and mist flow are some of the flow categories observed. For evaporating flow, the zone with bubbles smaller than channel diameter is very short as bubbles grow to the channel size very quickly.

Several studies have been reported in the recent years on vaporization in microchannels. Some experimental studies show that the heat transfer coefficients obtained during vaporization in microchannels are not a function of vapor quality nor mass velocity (in 
contrast with the macro-channel trend), but are a function of heat flux and saturation pressure (Kandlikar 2004, Thome 2004, Thome 2006). Other experimental studies demonstrate that the heat transfer coefficient also depends on vapor quality and mass velocity. Some experimentalists conclude that flow in small channels is dominated by nucleate boiling while forced convection evaporation is less important. Instead, Thome (2004) suggests that transient evaporation of the thin liquid films surrounding elongated bubbles is the dominant heat transfer mechanism.

Lee and Mudawar (2005) reported a list of studies on this matter showing that researchers are divided into two groups. The first group shares the view that nucleate boiling is dominant and therefore dictates overall heat transfer inside the channel. A second group shares the observation that the local heat transfer coefficient is a function of vapor quality and mass velocity in addition to heat flux. Of course, the understanding of dominant mechanisms during flow boiling in minichannels is the fundamental basis for the development of an accurate predicting method. Shiferaw et al. (2009) recently published flow boiling experiments in a $1.1 \mathrm{~mm}$ tube inside diameter using R134a. In their data, the heat transfer coefficient increases with heat flux, but does not change with vapour quality when the quality is less than about 30 to $50 \%$. For vapour quality values greater than $50 \%$ and at high heat flux, the heat transfer coefficient decreases with vapour quality.

With reference to microchannel flow boiling databases in the open literature, it appears that most experimentalists use electrical heating. In practical applications, the heat flux may be an independent variable as under Joule-effect heating or it may be a dependent variable when it is transferred from a secondary fluid. However, most of the data available in the literature was measured by adopting Joule effect heating and thus by imposing the heat flux. This technique allows to measure the heat flux with high accuracy and also to easily embed thermocouples in the wall.

On the contrary, limited data is available in the literature for flow boiling in minichannels taken without fixing the heat flux. That data, measured with the use of a secondary fluid in the evaporation test section, was obtained mainly in multiport minichannels, and generally using the Wilson plot technique. The main shortcoming of the Wilson plot technique is the high experimental uncertainty for the heat transfer coefficients particularly when the leading thermal resistance is on the secondary fluid side. Furthermore, in the case of multiport tubes, the heat transfer coefficient measured with the indirect experimental method represents only an average value over the parallel channels, that sometimes may be not evenly fed, and does not give any information for the single channel.

A new experimental apparatus for the measurement of local heat transfer coefficient inside a single minichannel has been used by the present authors. The heat is transferred to the evaporating fluid by using a secondary circuit and thus by imposing the temperatures of the fluid.

For the determination of the local heat transfer coefficient, three parameters are measured: the local heat flux, the saturation temperature and the wall temperature. The heat flux is determined from the temperature profile of the secondary fluid in the measuring sector. The wall temperature is directly measured along the test section and the saturation temperature is measured in the adiabatic segments at the inlet and outlet of the test tube by means of pressure transducers.

The present heat transfer data may be interestingly compared against data obtained under Joule-effect heating and used in the comparison against predicting correlations available for flow boiling inside minitubes.

\section{Experimental procedure}

\subsection{Apparatus}

The test rig used for the experimental tests is depicted in Figure 1. It consists of the primary (refrigerant) loop and of two auxiliary loops: the cooling water loop and the heating water loop. The subcooled refrigerant from the post-condenser is sent through a mechanical 
filter and a dehumidifier into an independently controlled gear pump, which is magnetically coupled to a variable speed electric motor.

The fluid is pumped through the Corioliseffect mass flow meter into the test section as a subcooled liquid. The subcooled liquid enters the test section, which is made of two counter-flow heat exchangers: the first one (pre-section) is used to achieve desired inlet subcooling, the second one is the actual measuring sector.

The pressure is gauged through two digital strain gauge pressure (absolute and differential) transducers, connected to manometric taps to measure the fluid pressure upstream and downstream of the test tube.

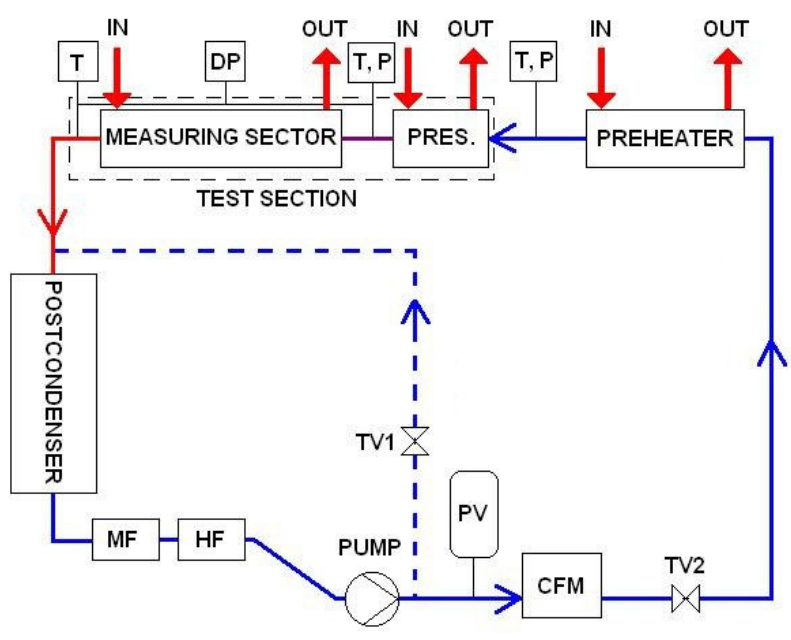

PRES. presection

MF mechanical filter

HF dehumidifier

PV pressure vessel

CFM Coriolis-effect mass flow meter

TV valve

$\mathrm{P} \quad$ pressure transducer

DP differential pressure transducer

Figure 1 - Experimental test rig
Two refrigerated thermal baths are used in the flow boiling tests: the first one provides the hot water entering the measuring section, the second one provides the coolant for the postcondenser. When necessary, the water entering the presection can be maintained at a different temperature through an additional electrical heater.

A picture of the minichannel test section is reported in Figure 2. This test section is obtained from a thick wall copper tube, with $0.96 \mathrm{~mm}$ inside diameter. The water passage is obtained by machining the copper on the external side.

The geometry of the water channel has been studied with the aim of increasing the external heat transfer area and thus decreasing the external heat transfer resistance. This complex flow passage (Figure 2) causes an internal local mixing of the water in the channel and thus high heat transfer coefficients by changing continuously the flow direction and disturbing the boundary layer.

The test section is designed for measurement of local two-phase heat transfer coefficients by measuring the local wall temperature and the water temperature profile along the channel. Therefore, the measuring sector is equipped with a high number of thermocouples, both in the wall and in the water.

The thermocouples embedded in the wall are installed in $0.6 \mathrm{~mm}$ diameter cylindrical holes, machined $0.5 \mathrm{~mm}$ far from the internal tube surface.

The measuring sector is thermally separated from the presection and the exit tube through adiabatic stainless steel capillary tubes.

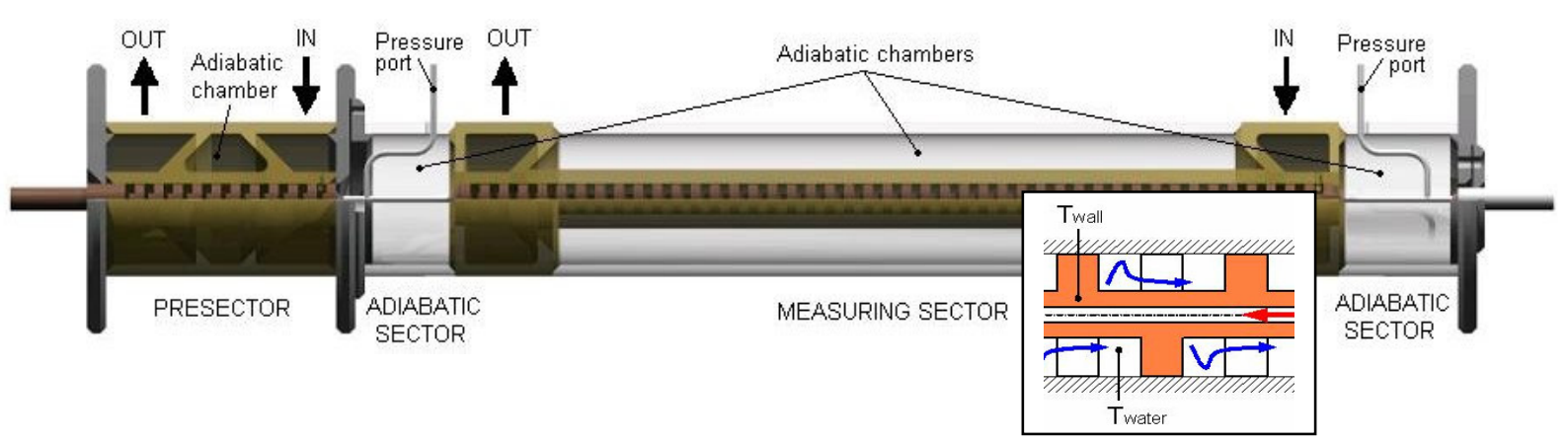

Figure 2 - View of the test section for circular minichannel and details of the water flow passage. 
The present design of the test section allows to embed several thermocouples in the tube without passing them through the water flow and thus preventing the thermocouple wires from being exposed to severe temperature gradients. Secondly, this design allows to measure the water temperature directly in the external annular space achieving an experimental accuracy comparable to the one of the temperature measurement carried out in a mixing cup.

The water flow rates, in the pre-section and in the measuring section, are measured by means of two Coriolis-effect mass flow meters and the total temperature difference of water across both sectors are measured with two copperconstantan thermopiles.

\subsection{Data reduction}

The local heat flux is determined from the temperature profile of the coolant in the measuring sector. Since the heat flux is not directly fixed here, it must be obtained indirectly, from the slope of the secondary fluid temperature profile:

$$
q^{\prime}=\dot{m}_{w} \cdot c_{p w} \cdot \frac{1}{\pi \cdot d_{i}} \frac{\mathrm{d} T_{w}}{\mathrm{~d} z}
$$

where $\mathrm{z}$ is the axial coordinate along the tube and $\mathrm{d} T_{w} / \mathrm{d} z$ is the derivative of the water temperature along $z$. In the calculation, a polynomial function is used to interpolate the water temperature profile along the channel. A sensibility analysis has also been performed to show the effect of the polynomial grade on the heat flux.

The local heat transfer coefficient inside the minichannel is obtained as the ratio of heat flux to temperature difference:

$$
\alpha_{i}=\frac{q^{\prime}}{\left(T_{\text {wall }}-T_{\text {sat }}\right)}
$$

The wall temperature $\left(T_{\text {wall }}\right)$ is measured by means of thermocouples embedded in the copper tube.

The saturation temperature is the local value in the exact position where the wall temperature is measured and the heat transfer coefficient is determined. The saturation temperatures at inlet and outlet are obtained from the pressure measurements. Along the channel, the pressure profile is calculated by implementing a twophase pressure gradient correlation between inlet and outlet. The calculated pressure profile is properly corrected in order for the total pressure drop to match the value measured by the differential pressure transducer.

The vapor quality $x$ at any axial position $z$ is obtained from:

$$
x=\frac{q-\dot{m}_{r} \cdot\left(h_{S L}-h_{\text {sub }}\right)}{\dot{m}_{r} \cdot h_{L G}}
$$

as a function of the total heat flow rate $q$ up to that location, the specific enthalpy of saturated liquid $\left(h_{S L}\right)$, the specific enthalpy of the subcooled liquid $\left(h_{s u b}\right)$ and the latent heat $\left(h_{L G}\right)$. The enthalpy of the subcooled refrigerant is determined from the inlet pressure and temperature, while the total heat flow rate transferred to the refrigerant is obtained by integrating the local heat flux $q$ ' from 0 (refrigerant inlet) to $z$.

$$
q=\pi \cdot d_{i} \cdot \int_{0}^{z} q^{\prime} \mathrm{d} z
$$

The total heat flow rate transferred to the refrigerant up to a certain location can also be checked from the thermal balance on the coolant side by using the water temperature difference between the given location $(z)$ and the outlet $(z=0)$ :

$$
q=\dot{m}_{w} \cdot c_{p w} \cdot \Delta T_{w, z}
$$

On-site calibration of the thermocouples installed in the wall and in the water channel has been carried out, in order to improve the accuracy of the measurements, especially with regard to the temperature difference among them. The major contribution to the experimental uncertainty of the heat transfer coefficient is due to the uncertainty associated with the heat flux, which in turn depends on the uncertainty of the water temperature gradient. The other components of the overall uncertainty are associated with the wall to saturation temperature difference, the hydraulic diameter and the refrigerant mass flow rate.

In the present experimental technique, the experimental uncertainty associated with the temperature difference between wall and 
saturation is reduced since the particular geometry of the coolant channel reduces the thermal resistance on the coolant side. As it can be seen from Figure 3, the boiling side presents the governing resistance.

Data reduction also accounts for the wall thermal resistance between thermocouple location and inner surface.

By operating an on-site calibration of the thermocouples, it is possible to reduce the uncertainty associated with the measurement of the water temperature and the average experimental uncertainty associated with the heat flux can be estimated equal to $\pm 10 \%$. Since the maximum uncertainty associated with the wall minus saturation temperature difference is $\pm 6 \%$ (at refrigerant inlet), the experimental uncertainty of the heat transfer coefficient is within $\pm 12 \%$ for most of the data points.

\section{Experimental results}

\subsection{Effect of heat flux}

Flow boiling tests have been performed with R245fa at mass velocity ranging between 200 and $400 \mathrm{~kg} \mathrm{~m}^{-2} \mathrm{~s}^{-1}$, around $31^{\circ} \mathrm{C}$ saturation temperature, in a $0.96 \mathrm{~mm}$ round channel.

During the test runs, mass velocity and inlet fluid temperature can be maintained constant, while the heat flux varies along the process. Figure 3 reports water, wall and saturation temperatures during a test run. Since R245fa and water flow in counter-current, the heat flux usually increases along the channel in the R245fa flow direction. Figure 4 reports heat flux, vapor quality and heat transfer coefficient referred to the test run of Figure 3.

In some test runs, the refrigerant exits as superheated vapor or saturated vapor with high quality. In this case, the heat flux increases with vapor quality in the channel up to a certain point, where the wall starts to dry up and the wall temperature deviates from its trend to approach the water temperature.

All the data points reported in the present paper refer to boiling conditions before the dryout occurs. The determination of the critical conditions in the present tests is done by looking at the standard deviation of the wall thermocouples, as described in Del Col et al. (2008).

At constant mass velocity and saturation temperature, the test runs have been performed by varying the inlet temperature of the water in order to vary the heat flux. The test runs have been performed in a double mode: by increasing first the temperature difference between inlet water and saturated refrigerant and then by decreasing it.

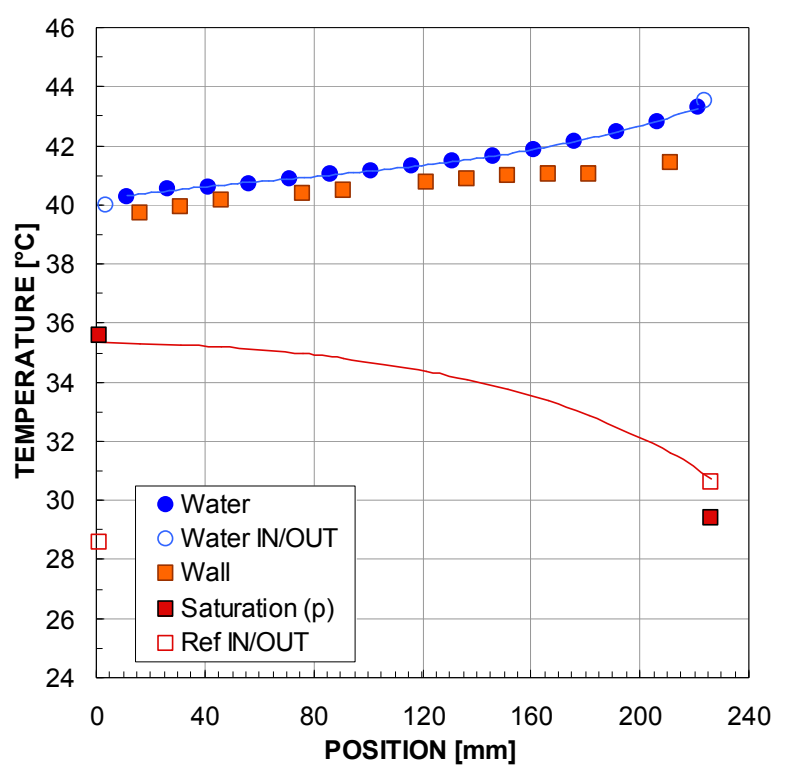

Figure 3 - Water, wall and saturation temperatures during the boiling process of $\mathrm{R} 245 \mathrm{fa}$ at $\mathrm{G}=300 \mathrm{~kg} \mathrm{~m}^{-2} \mathrm{~s}^{-1}$. Inlet and outlet temperatures of the refrigerant are also directly measured (Ref IN/OUT).

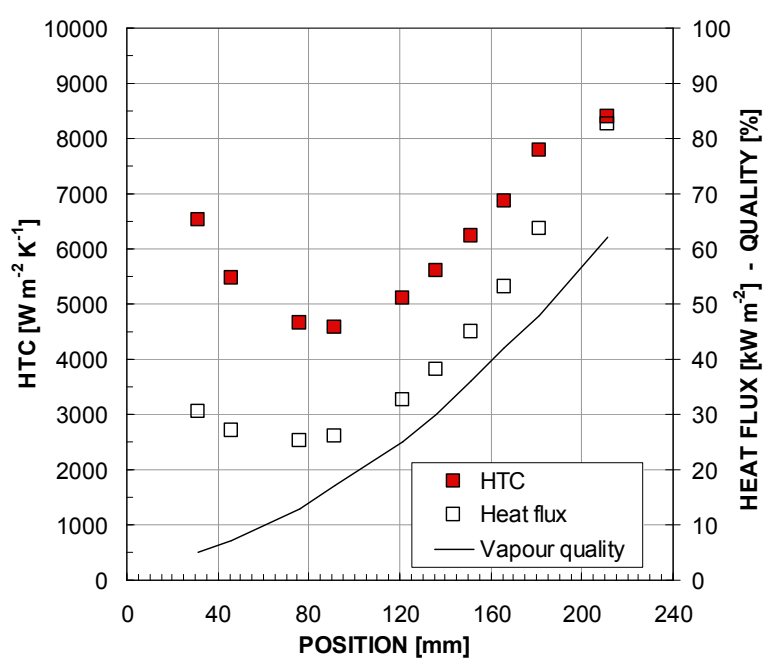

Figure 4 - Heat transfer coefficient, heat flux and vapor quality versus axial position at $\mathrm{G}=300 \mathrm{~kg} \mathrm{~m}^{-2} \mathrm{~s}^{-1}$. 
No hysteresis effect of the heat flux variation on the flow boiling heat transfer coefficients has been found.

The effect of axial conduction on the heat transfer coefficient has been determined from an energy balance at the wall, using the measurement of the wall temperature along the channel. It was determined that the axial conduction does not affect the values of heat flux neither the heat transfer coefficient, provided that dryout is not occurring in the channel.

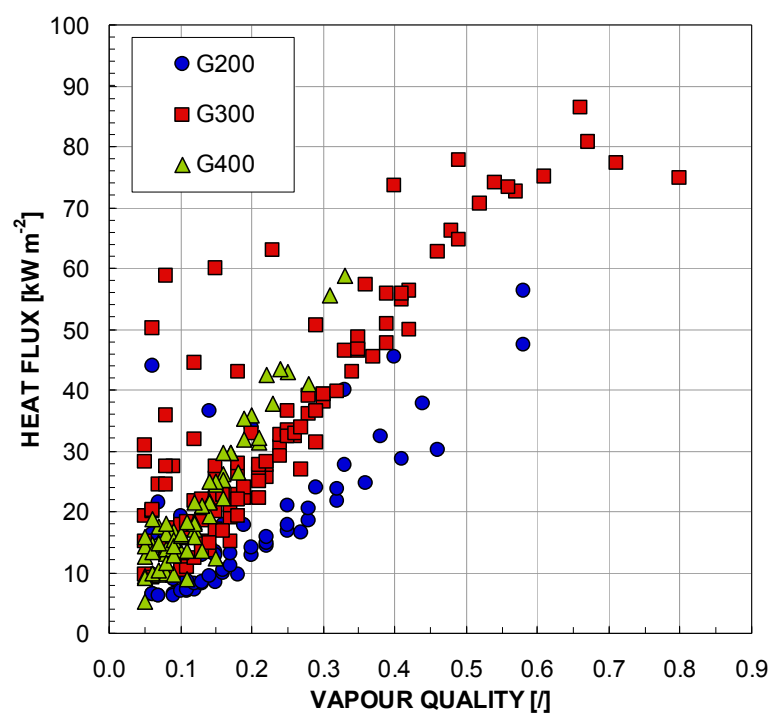

Figure 5 - Flow boiling data of R245fa at $\mathrm{T}_{\mathrm{sat}}=31^{\circ} \mathrm{C}$ : local heat flux versus vapour quality.

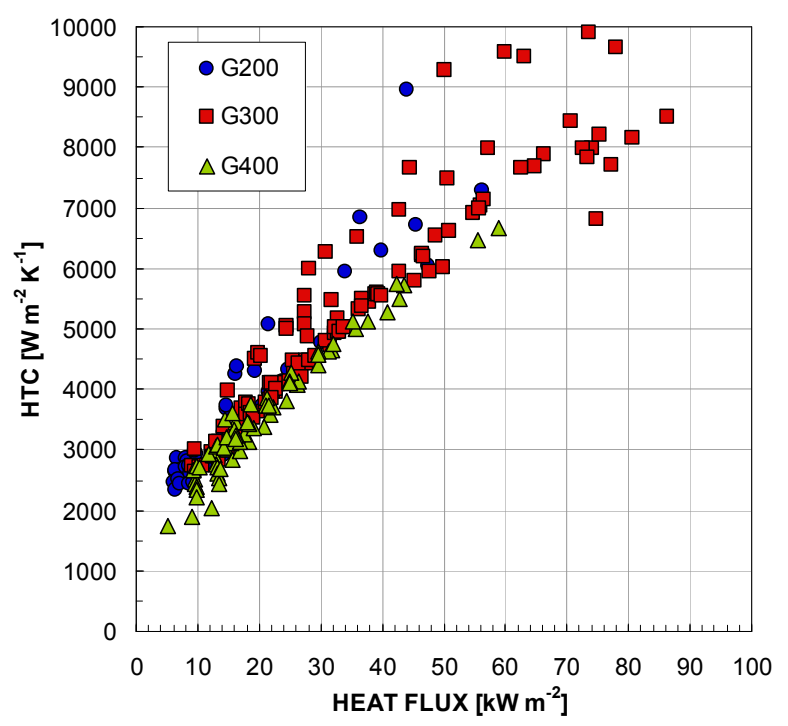

Figure 6 - Flow boiling data of R245fa at $\mathrm{T}_{\mathrm{sat}}=31^{\circ} \mathrm{C}$ : local heat transfer coefficients versus heat flux.
The graph in Figure 5 shows the heat flux plotted versus vapor quality for all the R245fa tests performed in the channel. Vapor quality varies between 0.05 and 0.85 , while the heat flux ranges from 5 up to $85 \mathrm{~kW} \mathrm{~m}^{-2}$.

When the same database is plotted as heat transfer coefficient vs. heat flux (Figure 6), all the data points lay in a pretty narrow band, showing a clear dependence of the heat transfer coefficient on the heat flux: the higher the heat flux, the higher the heat transfer coefficient. Only at higher values of heat flux, when the vapor quality span increases, the scattering increases too, showing a possible dependence of the heat transfer coefficient on the vapor quality.

In the analysis of present data, it should be considered that the average roughness in the present channel is equal to $\mathrm{Ra}=1.30 \mu \mathrm{m}$. The surface roughness is known to be important in the nucleation process: the smoother the surface, the larger the nucleation superheat (and heat flux) required to activate boiling sites. Similarly, the surface roughness must play a role in microchannel boiling, although its effect is not completely understood and agreed upon yet.

From Figure 6, one can see that the heat transfer coefficient increases with heat flux and it seems to be higher at lower mass velocity. Nevertheless, the effect of vapor quality and mass velocity requires that data are appropriately filtered in order to make it clear.

\subsection{Effect of vapor quality and mass velocity}

By processing data at constant heat flux, it is possible to get some information on the influence of vapor quality.

Figure 7 shows the experimental trend of heat transfer coefficient at $300 \mathrm{~kg} \mathrm{~m}^{-2} \mathrm{~s}^{-1}$ mass velocity, at different values of heat flux. The heat transfer coefficient decreases with vapor quality, for all heat flux conditions, from 30 up to $78 \mathrm{kWm}^{-2}$. In Figure 8 data have been filtered at constant heat flux and constant vapor quality. At 0.1 vapor quality, the heat transfer coefficient is slightly higher at lower mass velocity. A similar trend was evidenced at 0.3 vapor quality. 


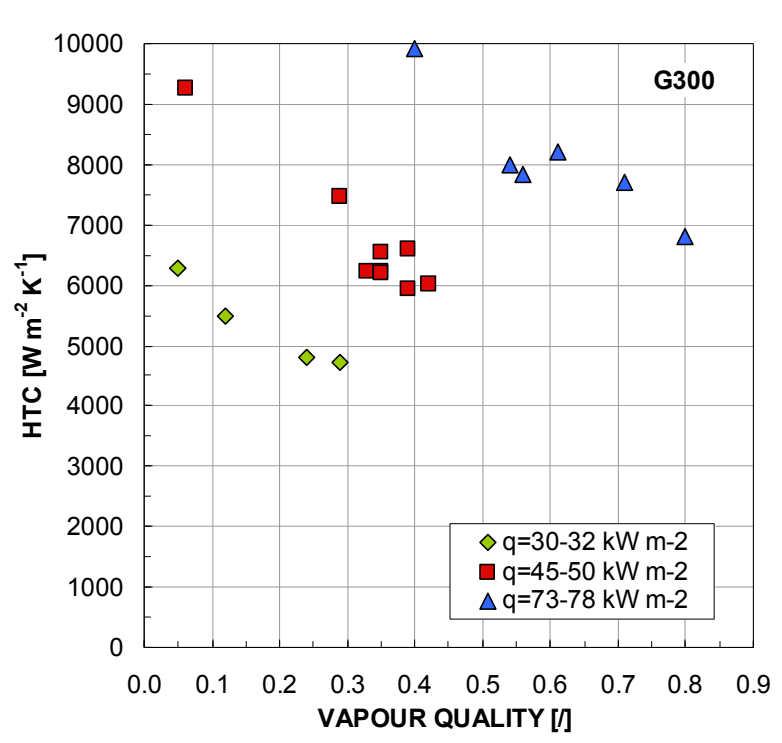

Figure 7 - Local heat transfer coefficient versus vapor quality at $300 \mathrm{~kg} \mathrm{~m}^{-2} \mathrm{~s}^{-1}$ and constant heat flux.

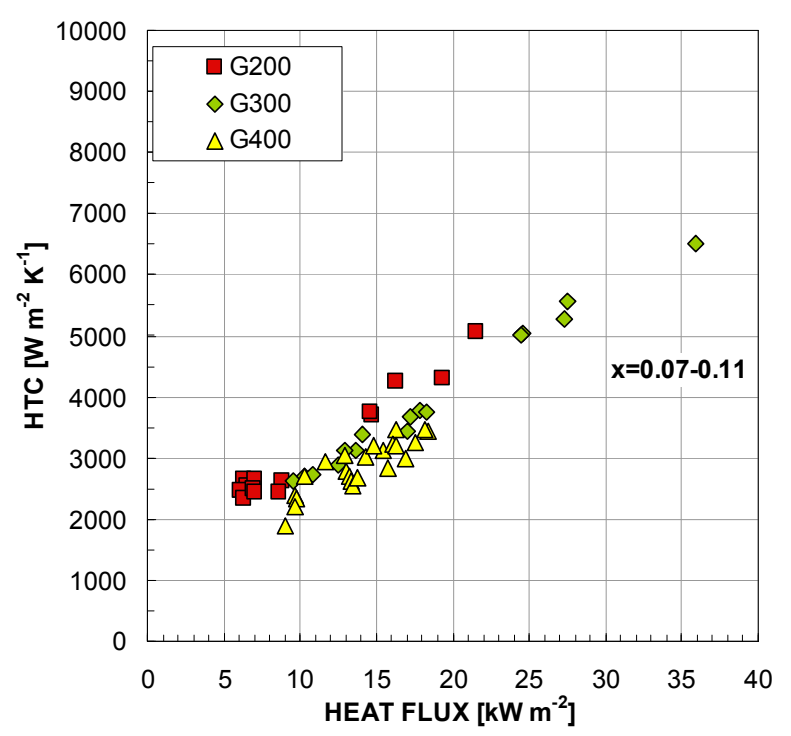

Figure 8 - Local heat transfer coefficient versus heat flux at constant vapor quality.

\section{Comparison with models}

Some comparisons have been made between present data and two models available in the literature. Among others, the models by Lazarek et al. (1982) and Thome et al. (2004) have been considered. Both models underpredict the experimental values of the heat transfer coefficient, although not to the same extent and not uniformly for the database.

The comparison with Lazarek et al. (1982) is shown in Figure 9: data points are underpredicted, with average deviation equal to $-24 \%$ and standard deviation equal to $9.2 \%$. On average, this model seems to be able to predict the experimental trend versus heat flux, while it does not catch the experimental trend versus vapor quality since the disagreement between predictions and experiments depends on vapor quality.

The comparison with the model by Thome et al. (2004) is shown in Figure 10: when increasing the heat flux the scattering is low but the disagreement between model and data tends to increase.

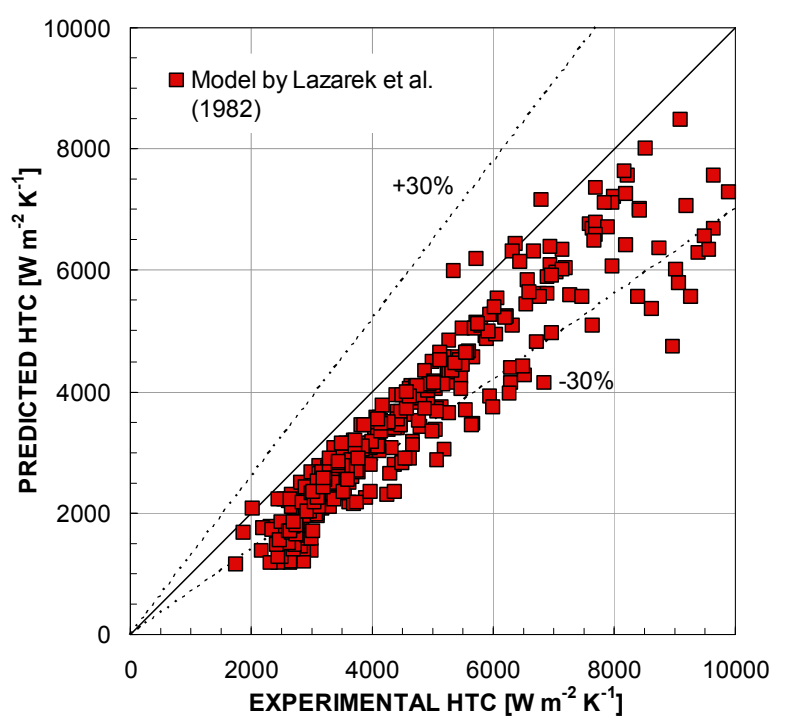

Figure 9 - Comparison with the model by Lazarek et al. (1982).

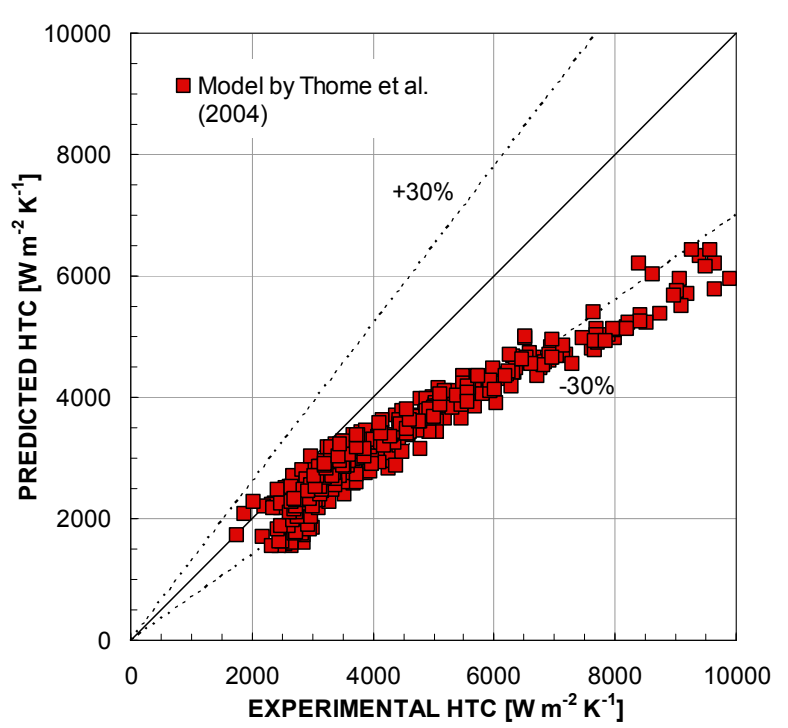

Figure 10 - Comparison with the model by Thome et al. (2004). 
On the contrary, this model is able to catch the experimental trend with vapor quality, displaying a constant underprediction in the range 0.3 to 0.8 vapor quality. The average deviation is equal to $-23 \%$, while the standard deviation is equal to $9.5 \%$.

\section{Conclusions}

In the present paper the authors describe a different experimental technique to measure the flow boiling coefficient in a $0.96 \mathrm{~mm}$ diameter single circular minichannel, using a secondary fluid instead of fixing the heat flux by electrical heating. The heat transfer coefficient at $31^{\circ} \mathrm{C}$ saturation temperature is measured with R245fa.

The heat transfer coefficient shows to be highly dependent on the heat flux while the effect of mass velocity is less important. With regard to the effect of vapor quality, the heat transfer coefficient decreases when vapor quality increases and this has been verified for a large range of heat flux values (between 30 and $78 \mathrm{~kW} \mathrm{~m}^{-2}$ ).

Present data have been compared against the model by Lazarek et al. (1982) and the one by Thome et al. (2004). Both models underpredict the present data. This maybe related to the relative roughness of the present test channel, which must play a role in microchannel boiling although models do not account for that. The two models display similar disagreement with data, although the one by Thome et al. (2004) is better able to catch the experimental trend versus vapor quality.

\section{References}

Del Col D., Cavallini A., Bortolin S., Matkovic M., Rossetto L., 2008. Dryout during flow boiling in a single circular minichannel: experimentation and modelling, Proc. of ASME Heat Transfer Conference, August 10-14, Jacksonville, FL, USA.

Kandlikar S.G. 2004, Heat Transfer Mechanisms during flow boiling in microchannels, J. of Heat Transfer, Vol. 126, pp. 8-16.

Kandlikar S.G. and Grande W.J., 2003,
Evolution of microchannel flow passages thermohydraulic performance and fabrication technology, Heat Transfer Engineering, vol. 24, no. 1, pp. 3-17.

Kew P.A. and Cornwell K., 1997, Correlations for the prediction of boiling heat transfer in small diameter channels, Applied Thermal Engineering, vol.17, pp. 705-715.

Lazarek G.M., Black S.H., 1982, Evaporative heat transfer, pressure drop and critical heat flux in small vertical tube with R-113, Int. J. Heat Mass Transfer, Vol. 25, No. 7, pp 945960.

Lee J., Mudawar I., 2005, Two phase flow in high-heat-flux micro-channel heat sink for refrigeration cooling applications: Part Ipressure drop characteristics, Part II-heat transfer characteristics, Int. Journal of Heat and Mass transfer, 48, pp.928-955.

Thome J.R., 2004, Boiling in microchannels: a review of experiment and theory, Int. J. of Heat and Fluid Flow, Vol. 25, pp. 128-139.

Shiferaw D., T.G. Karayiannis, D.B.R. Kenning, Flow boiling in a $1.1 \mathrm{~mm}$ tube with R134a: Experimental results and comparison with model, Int. J. of Thermal Sciences 48 (2009) 331-341.

Thome J.R., 2006, State-of-the-art overview of boiling and two-phase flows in microchannels, Heat Transfer Engineering, 27 (9), 4-19.

Thome J.R., Dupont V., Jacobi A.M., 2004, Heat transfer model for evaporation in microchannels. Part I: presentation of the model, Int. J. of Heat and Mass Transfer, 47, 3375-3385.

\section{Nomenclature}

$\begin{array}{ll}c_{p} & \text { specific heat }\left[\mathrm{J} \mathrm{kg}^{-1} \mathrm{~K}^{-1}\right] \\ d_{i} & \text { inner diameter }[\mathrm{m}] \\ G & \text { mass velocity }\left[\mathrm{kg} \mathrm{m}^{-2} \mathrm{~s}^{-1}\right] \\ m & \text { mass flow rate }\left[\mathrm{kg} \mathrm{s}^{-1}\right] \\ q & \text { heat flux }\left[\mathrm{W} \mathrm{m} \mathrm{m}^{-2}\right] \\ T & \text { temperature }[\mathrm{K}] \\ x & \text { vapor quality } \\ z & \text { axial position }[\mathrm{m}] \\ \alpha, H T C & \text { heat transfer coefficient }\left[\mathrm{W} \mathrm{m}^{-2} \mathrm{~K}^{-1}\right] \\ \text { Subscripts } \\ r & \text { refrigerant } \\ \text { sat } & \text { saturation } \\ w & \text { water }\end{array}$

